\title{
Practice and Research of Flipped Classroom in the Teaching of Mechanical specialty in Independent College Songping Chen
}

\author{
Tan Kah Kee College Xiamen University, Zhangzhou 363105, China \\ send_me@126.com
}

Keywords: Flipped Classroom, Effective Teaching, Teaching Reform.

\begin{abstract}
With the concept of "student - centered" and the flexible teaching and learning methods, the flipped classroom is being favored by more and more educators which focus on students' individualized and comprehensive development. Based on the present situation of mechanical specialty in independent college, this paper applies the flipped classroom in the teaching practice to realize the effective teaching centered on students. It can excite students' interest in learning effectively, contribute the interactive relationship between teachers and students, embody the dominance of students, and improve students' self-learning ability. It also cultivates students' ability to learn independently, to identify problems, to solve problems, to collaborate in groups, and to expand their ability to innovate. It provides the train of thought for the teaching reform of the mechanical specialty in the independent college under the new situation, and also provides the reference to the university to apply the training of innovative talent.
\end{abstract}

\section{翻转课堂在独立学院机械专业教学中的实践与研究}

\author{
陈松平 \\ 厦门大学嘉庚学院, 漳州, 福建, 中国 \\ send me@126.com
}

关键词：翻转课堂; 有效教学; 教学改革

中文摘要. 翻转课堂以其 “以学生为中心” 的教育理念、灵活的教与学的方式、关注学生个 性化与全面化发展的思想, 受到越来越多教育工作者的青睐。本文结合独立学院机械专业现 状, 将翻转课堂运用在课程教学实践中, 实现以学生为中心的有效教学。有效地激发了学生 学习的兴趣, 加强了教师与学生的互动, 凸显学生学习的主体地位。培养学生的自主学习能 力、发现问题、解决问题能力、小组协作能力以及拓展创新能力。为新形势下独立学院机械 类专业教学改革提供思路，也为高校应用创新型人才培养提供参考。

\section{1. 引言}

习近平在中国科学院第十七次院士大会、中国工程院第十二次大会上说过，要“坚定不 移创新创新再创新，加快创新型国家建设的步伐” ${ }^{[1]}$ 。创新型国家建设的关键在于创新人才 的培养，要把我国建设成为机械制造强国，其关键是培养适应制造业发展要求的新型机械制 造科技人才。在这样的背景下，独立学院作为高等教育的重要组成部分，对机械类应用创新 人才培养就显得尤其重要和迫切。近几年，翻转课堂已发展成为全球公认、备受关注的理想 课堂教学形态之一, 堪称当代世界课堂教学形态的典范之作。以 “学” 为主、 “教” 为辅, 
将课前、课中和课后有效结合, 开展 “以学生为中心” 的学习活动, 同时充分发挥教师的主 导作用 ${ }^{[2]}$ 。结合学院所在地区域特色制定了机械专业人才培养目标 “以创新设计和工程 实践能力为培养为主线, 以机械工程领域应用型人才为培养目标, 为海峡西岸经济区建设提 供高素质专业人才。”围绕这一人才培养目标, 转变和更新教育观念, 突破传统课堂的灌输 式教育模式, 构建以校内外实践基地为基础, 以创新项目、竞赛项目及企业技改项目为载体, 采用翻转课堂教学法, 达到工程技能、创新能力综合培养的人才培养新思路, 真正实现了以 学生为中心 “做中学”、“学中做”、“做中思”和“思中创”的有效教学。

\section{2. 翻转课堂在专业课程教学实践与研究}

\section{1 现状}

经过几十年探索与改革，目前我国高校机械类专业人才培养方案形成了加强基础、拓宽 专业、增强适应性、强化素质教育、注重能力培养、注重工程实践教学、鼓励培养模式多样 化等几方面的特色 ${ }^{[3]}$ 。然而, 目前独立学院机械类专业课程建设仍普遍存在以下问题: (1) 课程体系往往以强调学科逻辑发展的专业理论课程为主, 与教育目标在一定程度上不相关;

（2）专业课程之间仍然相对独立，课程建设与改革一般在各课程内部进行，无法越过学科壁 垒; (3) 专业课程群建设只是把相关的课程机械地组合在一起, 并未真正建立起有机联系, 更没有通过整合教学内容形成新的课程; (4) 教学观念陈旧, 教学方法拘泥, 教学形式单一。 传统教学观念随着国家对应用型人才需求和现代教育技术的发展已经不能很好地服务于创新 型人才培养, 往往还是一味地坚守陈旧的知识和经验累积起来的教育思想和理念, 强调 “听 中学” 的传统教学模式, 教师决定着教学的方向和内容, 掌握着教学目标和教学进度, 没有 留给学生独立思考的时间和空间, 处于一个被动接受知识的地位, 对课程内容的学习、理解 程度还不够深入, 导致学生被动地接受知识, 缺乏举一反三的能力。这样教师辅之以个别化 帮助也因课堂时间受限, 抑制了学生主动学习的积极性, 再加上学生个体差异的存在, 直接 导致了部分学生掉队。另一方面由于教学课时的限制, 学生实践也以验证型实验为主, 很难 有机会进行综合型实验, 更谈不上实际的工程应用, 从而造成学生在动手能力、主动学习能 力、创新能力不强等, 不利于应用创新型人才的培养。

\section{2 翻转课堂教学模式的设计与实施}

\section{2 .1 教学模式的提出}

提升教育教学质量一直是高等教育的永恒主题。根据独立学院机械设计制造及其自动化 专业人才培养方案和专业课程群课程理论知识抽象、课时压缩严重、实践性强、课程前后衔 接紧密等特点, 结合笔者多年的专业课程教学经验, 在教学过程中将传统的学习过程中的知 识传授和知识内化这两个阶段进行颠倒, 即学生课前通过教学视频、教学资料完成知识的传 授, 而课堂中学生通过分组讨论、习题、难点答疑等多种教学形式实现知识的内化, 即实施 翻转课堂的教学模式 ${ }^{[4]}$ 。这样的学习模式, 将课堂还给学生, 学生是中心, 有一个明确的项 目，在项目实施过程中，教师、实验技术人员会经常检查、督促项目进度，给予指导，帮助 学生完成项目。从学生的知识、技能、态度三方面培养学生就业的竞争力, 体现了高效率和 优效果的能力培养模式。

2.2.2 教学模式的设计

翻转课堂教学模式是通过师生之间的教与学的活动, 来帮助学习者解决学习活动中的问 题, 结合机械专业课程特点, 建立如图 1 所示的翻转课堂教学模式, 将整个翻转过程分为课 前、课中和课后三个阶段, 分别以教师活动和学生活动为主线, 将教师的教学准备、知识传 递、指导内化和教学反思四个环节和学生的知识获取、知识内化和学习总结三个环节形成一 


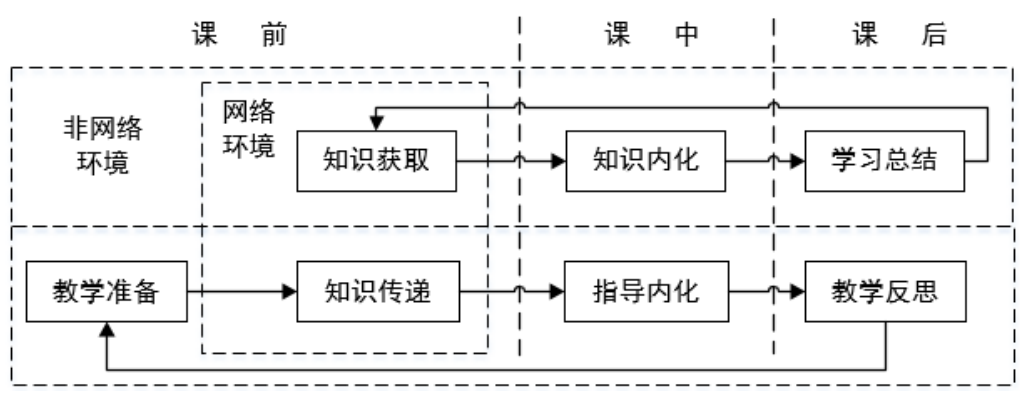

图1 翻转课堂的教学模式

\subsection{3 翻转课堂的实施}

本部分选取具有理论和实践环节的数控技术及应用专业课程作为应用案例说明翻转课堂 教学模式的实施过程。具体的实施分为课前、课中和课后三个过程, 如图2所示, 教师是学 习活动的组织者和引导者, 学生是学习活动的主体, 在校园教学网站和微信交流平台支持下, 教师和学生通过完成自己的角色任务来实现知识的传授和学习。课前环节构成要素有教师制 作数控编程和数控机床操作的教学微视频、设计各知识点课前自主学习任务单和学生按要求 观看教学微视频和课件等资料、完成课前自主学习任务单、标记疑惑提出问题等。课中分理 论课和实践课, 理论课主要是学习内容热身、小组协作完成项目任务、学习成果展示与师生、 生生之间的交流解决课前所记录的知识点疑惑。实践课则由学生自主实现各级任务, 教师和 实验员辅导答疑和评价反馈等。课后主要有学生制作作品、学生分享作品、教师评价作品、 学生互评作品等要素构成, 利用微信公众号构建第二课堂交流平台, 学生对遇到的问题和需 要注意的地方跟同学分享, 教师则对知识点中的重难点进行系统化归纳, 潜移默化中提高学 生解决问题的能力。教学大纲在数控编程部分要求学生掌握典型零件的数控车床、铣床和加 工中心程序的编制方法, 并能应用计算机辅助编程, 完成零件的数控加工。根据教学目标, 教师将数控车床编程的项目任务单设计为三个项目: 基础项目为加工一件 45 钢材料工艺轴, 达标项目为加工二级减速器传动轴, 拓展项目则为数控车工技师技能鉴定考核题, 由浅入深、 循序渐进，使学生始终感到有能力完成项目，激发学生挑战项目的欲望。每级项目都结合一 个具体的零件, 把项目任务布置给学生, 要求在课前熟悉项目任务、明确工作内容、查阅相 关资料并明确加工方案; 在课中, 以小组为单位阐述整个零件的加工方案, 如制订加工工艺 方案（包括毛坏准备、机床选择、确定工艺参数、工装夹具、刀具、量具选择等）、展示工 艺卡和工序卡、加工程序和数控模拟仿真加工结果, 教师对各组展示的情况进行点评, 根据 存在的问题进行个性化指导; 课后学生根据任务完成的情况, 提交学习报告并则通过平台进 行提交, 参与学生的自评、互评和教师、实验员或工程师的批阅, 整理课中任务实施中遇到 的问题, 对整个学习过程进行反思、总结和改进。通过课程考核和在线调查表明, 翻转课堂 教学法有效提升了学生的专业能力、实践能力、团队协作和语言表达能力, 教学效果显著。

课 前

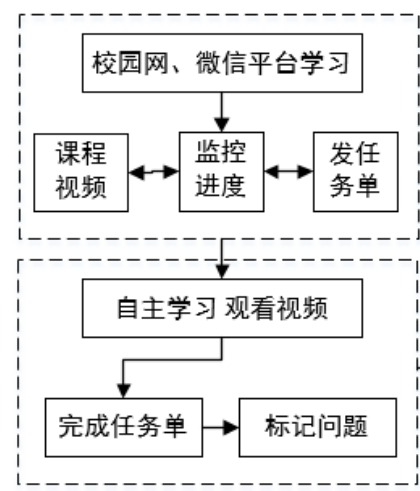

课 中

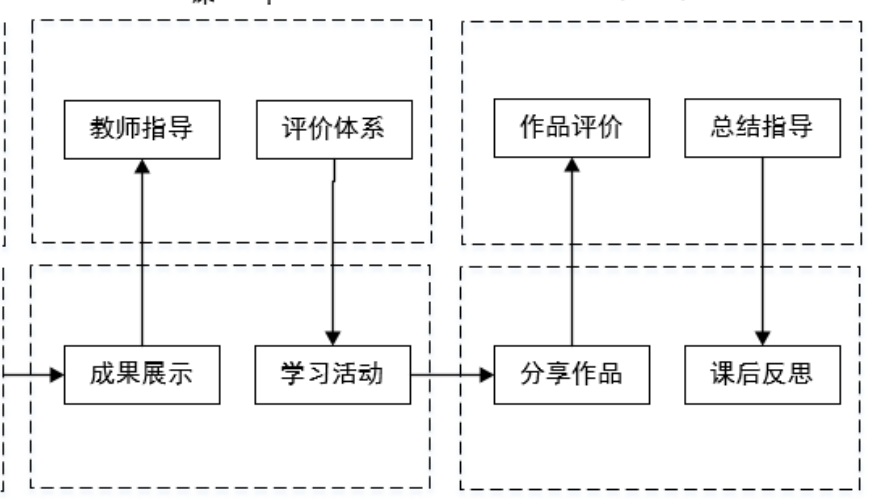

图2 翻转课堂教学模式实施过程 


\subsection{4 建立多元化的课程评价策略}

传统的课堂教学是由任课教师来考评学生, 重在知识的获得, 对教学过程的关注不够。 而翻转课堂教学质量的评价体系则重在能力培养, 能力本位的教学观贯穿理论和实践教学的 全过程, 注重从评价材料、评价主体等方面的多元化发展 ${ }^{[5]}$ 。因此必须确保能力评价过程的 客观性、完整性、合理性、有效性和可操作性，采用不同的方法评价不同的能力。以工程图 学、数控机床及应用、机械原理和机械设计课程为例, 构建了 “前期评价、同伴互评、自我 评价和期末评价” 的四级评价体系。课前, 采用前期评价对学习成果进行评价, 往往可利用 教学视频内嵌的习题或者课中通过简单的测验进行评价; 课中，根据完成任务单的情况和知 识内化能力, 学生除了接受自我评价和同伴互评外, 还需接受老师、实验员、专业考评员或 企业工程师等交叉评价, 客观真实地反映个体的学习能力和效果; 课后, 一方面利用学生评 价模块对学生学习过程和学习结果进行综合评价。学习过程评价模块由项目任务单完成情况、 课前视频观看、课前训练与测试等组成, 学习结果评价模块则由项目作品展示、阶段学习报 告、课堂综合表现等组成。另一方面, 课后评价结合传统的单元测试和期末考试来检验学生 学习成果。这样的评价体系从课前、课中和课后对学生学习全过程进行评估, 改变以期末卷 面考试为主要评价依据的评价方式，逐步完善知识+技能+态度的考核方式。模拟企业项目开 发团队组建学习协作小组, 采取项目负责人制度, 负责本小组的任务分配、进度跟踪、质量 监控。项目完成后, 通过展示成果、学生互评、教师评价, 深化了学习成果, 提高了沟通能 力。整个评价体系将学生的基本个人专业综合能力和人际能力, 产品、过程和系统构建能力 以及学科知识融为一体, 并将考核和评价结果反馈给学生、教师和教学管理者, 以更好促进 专业教学改革的可持续发展。

\section{3. 结束语}

尽管翻转课堂教学模式实施中仍存在着些小问题, 如少部分学生课前主动学习能力差、 信息化环境建设还不完善等问题, 但相对于传统教学模式而言是一种前所未有的挑战, 教师 要结合学科、课程和学生的实际情况, 合理运用翻转课堂教学模式, 与传统教学更好地结合 在一起, 才能将教师从讲台上解放, 把课堂真正还给学生, 实现以学生为中心的有效教学。 这样不仅能提高学生自主学习的积极性, 锻炼自主创新能力, 也能培养了学生的团队协作、 职业道德和职业素养。

\section{References}

[1] Jinping Xi. Speech at the 17th Meeting of Academicians of the Chinese Academy of Sciences and the 12th Academician Conference of the Chinese Academy of Engineering. http://cpc.people.com.cn/n/2014/0610/c64094-25125594.html, 2014.

[2] Yi Chen, Chengling Zhao. An instructional design and application research based on the flipped classroom model. Modern Educational Technology. vol. 3, pp. 49-54, 2004.

[3] Huifen Lai, Exploration and research on the reform of talent cultivation program of mechanical design and manufacture and automation in independent college. Mechanical and Electrical Engineering Technology, vol.11, pp. 119-121, 2010.

[4] O`Flaherty, J. \& Phillips, C, The use of flipped classrooms in higher education: A scoping review. The Internet and Higher Education, vol. 6, pp. 85-95, 2015.

[5] Brunsell, E., Horejsi, M, A flipped how classroom in action. Washington: The Science, Teacher vol. 8, pp. 8-11, 2013. 